\title{
Characterizations of aluminum-promoted sulfated zirconia on mesoporous MCM-41 silica: Butane isomerization
}

\author{
Jung-Hui Wang, Chung-Yuan Mou * \\ Department of Chemistry and Center of Condensed Matter Science, National Taiwan University, Taipei 106, Taiwan
}

Received 16 August 2006; received in revised form 2 January 2007; accepted 10 June 2007

Available online 30 June 2007

\begin{abstract}
Sulfated zirconia (SZ) was supported on mesoporous molecular sieves MCM-41 by impregnation of zirconium sulfate followed by calcination. The nanochannels of MCM-41 provide a large surface area for the solid state dispersion of zirconium sulfate and a steric restriction on formation of zirconia nanoparticles. The catalysts were tested in $n$-butane isomerization. With the addition of a proper amount of alumina as a promoter, denoted as ASZ/MCM-41, the catalytic activity was dramatically improved in comparison to the activities of SZ/MCM-41. The increase of activity was determined primarily by the amount of aluminum added and the temperature of calcination. The SZ/MCM-41 catalysts were characterized by X-ray diffraction (XRD), high resolution TEM (HR-TEM), $\mathrm{NH}_{3}$ adsorption ( $\mathrm{NH}_{3}$-TPD), X-ray photoelectron spectroscopy (XPS) and X-ray absorption (EXAFS). In particular, the Zr K-edge EXAFS data give one a measure of the degree of dispersion of zirconia on the surface of MCM-41. The trend of the promotion effects of alumina on SZ in butane isomerization is not monotonic; there is an optimum level of Al-loading for high activity. It is explained based on three quantitative factors: increased sulfur loadings, balanced distribution of Lewis and Brønsted acid sites, and higher dispersion of zirconia. (C) 2007 Elsevier Inc. All rights reserved.
\end{abstract}

Keywords: Aluminum; Sulfated zirconia; Mesoporous; MCM-41; Butane; Promoter; Isomerization

\section{Introduction}

Skeletal isomerization of alkanes catalyzed by a solidacid is important for the production of clean-burning fuels of high octane number. In recent years, researchers have been interested in solid acid catalysts to search for stable and environmentally friendly catalysts. Among the solid acids, sulfated zirconia $\left(\mathrm{SO}_{4}^{2-} / \mathrm{ZrO}_{2}\right.$, abbreviated as $\left.\mathrm{SZ}\right)$ has attracted considerable interest because it is more active and selective for the transformation of hydrocarbons at low temperature $[1,2]$. Comparing with liquid acid catalysts, such as $\mathrm{HF}$ and $\mathrm{H}_{2} \mathrm{SO}_{4}$, sulfated zirconia is more environmentally friendly.

An important factor affecting the performance of the solid acid catalyst is its degree of dispersion which affects

\footnotetext{
* Corresponding author. Tel.: +88623366 5251; fax: +88622366 0954. E-mail address: cymou@ntu.edu.tw (C.-Y. Mou).
}

the concentration and number of active sites. If SZ is synthesized by conventional route, it is difficult to have good control over its textural properties. For example, typically the surface area for active SZ is less than $100 \mathrm{~m}^{2} / \mathrm{g}$ in the tetragonal crystalline phase. The number of active sites of sulfated zirconia is limited by the available specific surface area and degree of surface sulfation [3]. Recently, Sun et al. made nanosized sulfated zirconia with a higher surface area of $165 \mathrm{~m}^{2} / \mathrm{g}$ containing relatively more Brønsted acidic sites than conventional sulfated zirconia [4]. Catalytic activity for cumene cracking was thus higher [4]. Moreover, conventional SZ catalysts do not have uniform pore sizes. It would be of advantage to have sulfated zirconia supported on a mesoporous material of high surface area, such as MCM-41(SZ/MCM-41). It has been reported that the use of mesoporous silica as support can improve the catalytic properties of SZ for its better dispersion. However, much of the details in catalysis seem to depend on the pore size and morphology and the dispersion of zirconia [5-11]. 
More recently, with the addition of a proper amount of alumina as a promoter onto SZ/MCM-41, the activities of the catalysts (ASZ/MCM-41) in the isomerization of $n$-butane were further improved [12-16]. The role of the alumina promoter in the presence of hydrogen is still an unresolved issue. The catalytic behavior over un-promoted and promoted sulfated zirconia has been mostly discussed in terms of crystalline phase [5,6], sulfate content [6], and surface acidity $[12,14-16]$. It has been found that phase transformation of $\mathrm{ZrO}_{2}$ from tetragonal to monoclinic is retarded by the presence of $\mathrm{Al}$ [6].

Although there has been extensive focus on the factors of affecting the acidity of SZ in the past, there has been much less investigation on the effect of dispersion of zirconia [17]. Using the large surface area mesoporous MCM41 , we can disperse zirconia on its surface very extensively and it provides us an opportunity to study the effect of dispersion. With this, we would like to understand further the kind of acid sites in ASZ/MCM-41 and its relation to catalytic activities. Isomerization of $n$-butane to iso-butane was chosen as the test reaction to determine the relative catalytic activity of the various catalysts in this paper. Hua et al. [18] suggested that the stronger acid sites were associated with sites of low coordination of zirconium such as defect, corners or edges on the surface of particles. A quantitative determination of the site distribution would be desirable. Utilizing local structure and surface sensitive techniques, Extended X-ray absorption fine structure (EXAFS) and X-ray photoelectron spectroscopy (XPS), would permit us to determine the degree of dispersion of the catalyst and changes in the relative amount of acid sites respectively, as alumina addition was varied [14]. EXAFS technique, in particular, would provide one the information of local coordination and inter-atomic distances to characterize the dispersion of zirconic atoms. Finally, we discuss the trend of catalytic activity upon increasing loading of alumina and relate it to the changing dispersion of ZR and the acidity of the catalyst.

\section{Experimental}

\subsection{Sample preparation}

Alumina-promoted sulfated zirconia supported on MCM-41, designated as ASZ/MCM-41 (A and SZ standing for aluminum and sulfated zirconia), were prepared by impregnation method described in our previous report [19]. These catalysts were prepared as follows: first, a desired amount of zirconium/aluminum sulfate $(3.3896 \mathrm{~g} /$ $0.1718 \mathrm{~g}$ ) was solved in a mixture of $0.5 \mathrm{~g}$ de-ionized water and $2.5 \mathrm{~g}$ methanol. We impregnated about $2 \mathrm{~g}$ as-synthesized mesoporous MCM-41 materials in the above solution and stirred at room temperature for about $60 \mathrm{~min}$. Then, the mixture was dried overnight at $100{ }^{\circ} \mathrm{C}$. Secondly, controlled decomposition of the template remained in the mesoporous materials was performed by heating to $400{ }^{\circ} \mathrm{C}$ under static air for $5 \mathrm{~h}$ at a rate of $1.25{ }^{\circ} \mathrm{C} / \mathrm{min}$ and held at $400{ }^{\circ} \mathrm{C}$ for $5 \mathrm{~h}$ for a complete solid-state dispersion of zirconium/aluminum sulfate into pores of mesoporous materials. Finally, zirconium/aluminum sulfate was decomposed at $720{ }^{\circ} \mathrm{C}$ for $3 \mathrm{~h}$. The catalyst contained 50 $\mathrm{wt} \% \mathrm{ZrO}_{2}$, calculated on weight basis of the calcined MCM-41, which is close to the dispersion threshold of zirconium sulfate on MCM-41. The alumina-promoted catalysts are labeled as $x$ A50SZ/MCM-41 with $x$ corresponding to the nominal alumina concentration in mole percent based on the amount of $\mathrm{ZrO}_{2}\left(\mathrm{Al}_{2} \mathrm{O}_{3} / \mathrm{Al}_{2} \mathrm{O}_{3}+\mathrm{ZrO}_{2}\right)$. The unpromoted catalyst $50 \mathrm{SZ} / \mathrm{MCM}-41$ was made by the same process of 5A50SZ/MCM-41 except substituting ammonium sulfate $\left(\mathrm{NH}_{4}\right)_{2} \mathrm{SO}_{4}$ for aluminum sulfate $\mathrm{Al}_{2}\left(\mathrm{SO}_{4}\right)_{3}$ to retain the same amount of sulfur.

\subsection{Characterizations}

Using $\mathrm{Cu} \mathrm{K} \alpha(\lambda=0.154 \mathrm{~nm})$ radiation in a operate mode of $40 \mathrm{kV}, 30 \mathrm{~mA}$, the powder X-ray diffraction patterns (XRD) were recorded on a Scintag X1 diffractometer. The surface area and $\mathrm{N}_{2}$ adsorption-desorption isotherms were determined at $-196{ }^{\circ} \mathrm{C}$ with a Mircomeritics ASAP 2010 instrument. The specific surface areas were calculated according to the BET method and the pore size distribution curves were obtained from the BJH (Barrett-Joyner-Halenda) method.

Temperature-programmed desorption of ammonia $\left(\mathrm{NH}_{3}-\mathrm{TPD}\right)$ was performed on a AutoChem 2910 and Thermo ONIX ProLab system. In a conventional flow system, $50 \mathrm{~mL} / \mathrm{min}$ of helium was used as carrier gas. Prior to analysis, about $0.15 \mathrm{~g}$ of the catalyst sample was first activated in situ in a helium flow at $500{ }^{\circ} \mathrm{C}$ for $1 \mathrm{~h}$ to remove adsorbed water. Adsorption of probe molecule was then performed by introducing 3\% ammonia in He over the catalyst for $1 \mathrm{~h}$ at $110^{\circ} \mathrm{C}$. After the adsorption, the sample was purged for $1 \mathrm{~h}$. The reactor temperature was ramped up to $700{ }^{\circ} \mathrm{C}$ at a heating rate of $10^{\circ} \mathrm{C} / \mathrm{min}$ and the evolved ammonia was recorded by a TCD detector with a quadrupole mass spectrometer connected for simultaneous residual gas analysis. The working pressure is below $3 \times 10^{-7}$ Torr.

Transmission electron microscopy (TEM) micrographs were taken with a Hitachi $\mathrm{H}-7100$ instrument operating at $75-100 \mathrm{kV}$ or a Philips CM200 at $200 \mathrm{kV}$. The X-ray absorption spectra were measured with synchrotron radiation using the beamline BL12B2 at SPring8 in Japan. Spectra were recorded at room temperature in transmission mode. The EXAFS function was derived from the raw absorption data through pre-edge and post-edge background subtraction and then normalization with respect to the edge jump. All the computations were implemented in the software package of FEFF702. The EXAFS spectra were analyzed using the curved wave, single-scattering method and calibrated by using a zirconium foil as a standard at $17,998 \mathrm{eV}$. Structural parameters were obtained from the experimental $x(k)$ using least squares fitting in 
$k$-space with $k^{3}$ weighting and values of $k_{\min }=2.95 \AA^{-1}$ and $k_{\max }=15.45 \AA^{-1}$ were used for all samples.

$\mathrm{X}$-ray photoelectron spectroscopic analyses (XPS) were performed using a Thermo VG Scientific, ESCALAB 250 fitted with a monochromatic $\mathrm{Al} \mathrm{K} \alpha$ radiation $(1486.8 \mathrm{eV})$ X-ray source, under a residual pressure of $\sim 1 \times 10^{-9}$ Torr. Charge effect was compensated by the use of a flood gun. Calibration was then achieved by setting the $\mathrm{C} 1 \mathrm{~s}$ binding energy at $284.6 \mathrm{eV}$. The spectra were recorded for the $170-190 \mathrm{eV}$ region to determine the $\mathrm{Zr} 3 \mathrm{~d}$ and then de-convoluted into sub-bands (sum-function of Gaussian and Lorentzian, 50\% Gaussian, 50\% Lorentzian) with software, XPSPEAK, from RCSMS lab using an integrated background subtraction.

\subsection{Catalytic reaction}

The butane isomerization reaction was carried out in a fixed-bed continuous flow system under atmospheric pressure. Approximately $1.0 \mathrm{~g}$ of the catalyst (20/60 mesh) was loaded into the reactor and pre-treated in flowing air for $3 \mathrm{~h}$ at $450^{\circ} \mathrm{C}$. After decreasing and stabilizing the temperature to $250{ }^{\circ} \mathrm{C}$, the reactor was flushed with nitrogen for $30 \mathrm{~min}$ and finally fed with a mixture $1 / 10 \mathrm{v} / \mathrm{v} n$-butane $/ \mathrm{H}_{2}$ (WHSV $=0.31 \mathrm{~g}_{\text {butane }} \mathrm{h}^{-1} / \mathrm{g}_{\text {cat. }}$ ). The flow rate was controlled using a Brooks mass flow controller. The products were monitored and analyzed with a Shimadzu 14B gas chromatograph with a 60 m DB-1 column and FID detector.

\section{Results}

\subsection{Catalysts properties and activity}

The XRD profiles of all $x$ A50SZ/MCM-41 catalysts showed only the tetragonal $\mathrm{ZrO}_{2}$ phase. In contrast, the un-promoted SZ/MCM-41 shows mixed monoclinic and tetragonal phases. Many researchers reported that the tetragonal phase of zirconia is catalytically more active than the monoclinic phase [20-22]. The enhanced catalytic performance of alumina-promoted sulfated zirconia was attributed by Gao et al. [12] to the retardation from a metastable tetragonal zirconia phase to the thermodynamically favored monoclinic phase. Canton et al. [23] have examined the stabilization effect of alumina on the phase and size of zirconia with detailed Rietvelt analysis of X-ray diffraction results.
Table 1 lists the surface area, pore volume and pore diameter of MCM-41, 50SZ/MCM-41 and $x$ A50SZ/MCM-41 with various alumina contents. MCM-41 has a surface area greater than $1000 \mathrm{~m}^{2} / \mathrm{g}$, pore volume of $0.81 \mathrm{~cm}^{3} / \mathrm{g}$ and an average pore diameter around $2.7 \mathrm{~nm}$. It is observed that introducing sulfated zirconia to MCM-41 causes the surface area to decreases to almost half and the pore size narrows to $2.1 \mathrm{~nm}$. This indicates that the supported ASZ is indeed inside the channels of MCM-41 altering the diameter and the shape of pores. The textural properties seem to be fairly independent of the amount of alumina loaded. The sulfur contents are increasing with the amount of alumina loadings which is somewhat expected because $\mathrm{Al}_{2}\left(\mathrm{SO}_{4}\right)_{3}$ is used for the loading of both $\mathrm{Al}$ and sulfur. Without any $\mathrm{Al}$, the sulfur content in $50 \mathrm{SZ} / \mathrm{MCM}-41$ is $1.03 \%$ which is retained by zirconia. We assume alumina and silica do not retain sulfur. The increased sulfur retention upon alumina loading may indicate either better dispersion of zirconia to retain more sulfur on its surface. We will discuss the effect of dispersion of zirconia later.

The effect of the different loadings of alumina (3-7 mol\%) on the catalytic activity is shown in Fig. 1. It is observed that the addition of a small amount of alumina greatly improves the catalytic activity. At about $5 \mathrm{~mol} \%$ alumina loading, the highest catalytic activity (5A50SZ/MCM-41) was observed. One notices that although the initial conversion approached $60 \%$, it decayed rapidly to about half in $2 \mathrm{~h}$. Previously, for Al-promoted mesoporous zirconia we found that the optimum activity is at Al-content of 3\% [14]. There is relatively more bulk and less surface zirconia in mesoporous zirconia per unit zirconia weight [14] as compared to the more surface zirconia spread on MCM-41 in this work. We show in later section by EXAFS, the degree of dispersion of zirconia in Al-promoted SZ/MCM-41 is better than that in mesoporous zirconia. Thus it is reasonable to see the point of optimum activity shifts to Al-content of $5 \%$ for SZA/ MCM-41. The catalytic activities for all cases decayed gradually with time on stream, but all activities can be completely restored by thermal treatment in air at $450{ }^{\circ} \mathrm{C}$. The selectivity to isobutane was higher than $90 \%$ with minor amounts of methane, propane and pentane.

\subsection{Acidity}

We now turn our attention to the investigation of surface acidity of the SZ catalyst [24-26].

Table 1

Physico-chemical properties of MCM-41, 50SZ/MCM-41, and $x$ A50SZ/MCM- 41 catalysts calcined at $720{ }^{\circ} \mathrm{C}$ with various amount of alumina

\begin{tabular}{llllll}
\hline Catalysts & Surface area $\left(\mathrm{m}^{2} / \mathrm{g}\right)$ & Pore volume $\left(\mathrm{cm}^{3} / \mathrm{g}\right)$ & Pore diameter $(\AA)$ & Aluminum content $(\mathrm{wt} \%)$ & Sulfur content $(\mathrm{wt} \%)$ \\
\hline MCM-41 & 1022 & 0.81 & 27 & - & - \\
50SZ/MCM-41 & 483 & 0.36 & 22 & - & 0.41 \\
3A50SZ/MCM-41 & 524 & 0.39 & 20 & 0.55 & 1.03 \\
4A50SZ/MCM-41 & 491 & 0.38 & 20 & 1.09 \\
5A50SZ/MCM-41 & 451 & 0.36 & 21 & 0.61 & 1.27 \\
6A50SZ/MCM-41 & 509 & 0.42 & 22 & 0.84 & 1.67 \\
7A50SZ/MCM-41 & 497 & 0.39 & 22 & 0.97 & 1.85 \\
\hline
\end{tabular}




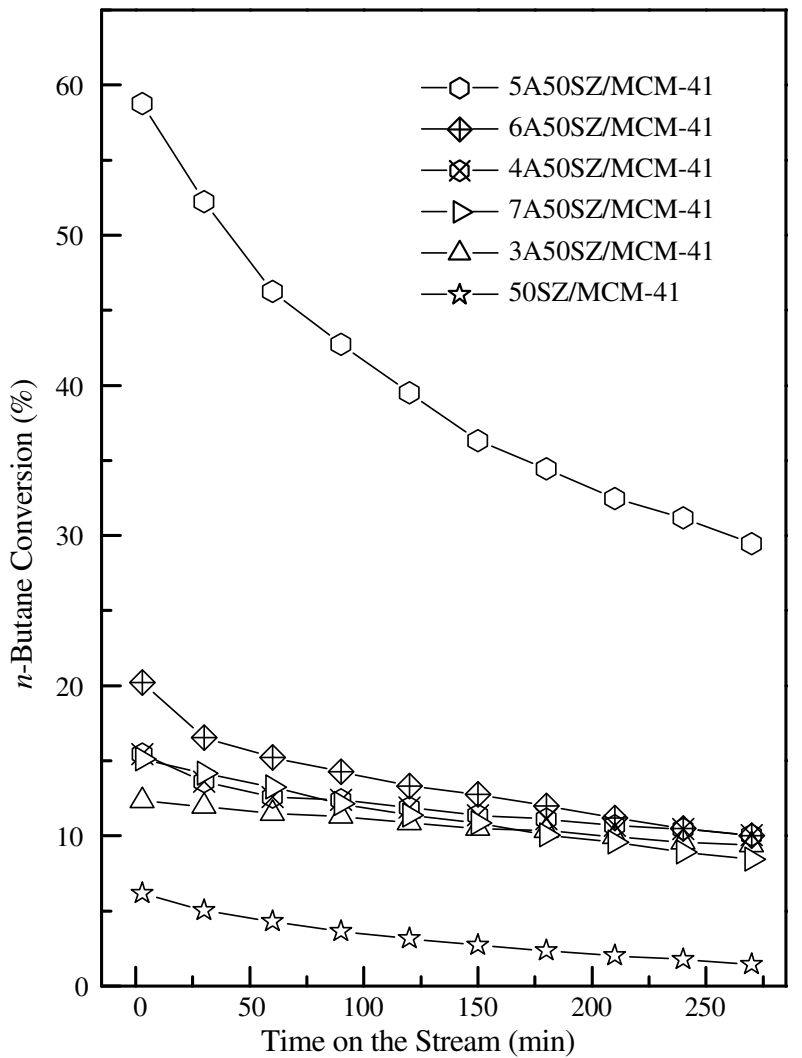

Fig. 1. The catalytic conversion of $x$ A50SZ/MCM-41 catalyst calcined at $720{ }^{\circ} \mathrm{C}$ with various alumina loadings. Reaction condition: reaction temperature $=250{ }^{\circ} \mathrm{C}, n$-butane $/ \mathrm{H}_{2}=1 / 10$ and $\mathrm{WHSV}=0.31 \mathrm{~h}^{-1}$.

Temperature-programmed desorption (TPD) of adsorbed ammonia was used to evaluate the strength and the amount of acid sites on $x$ A50SZ/MCM-41. A more detailed investigation by monitoring specific ions (TPD-MASS) was then performed. Fig. 2 a depicts two desorption TCD peaks appearing at 200 and $620^{\circ} \mathrm{C}$. However, TCD signals may also include desorption of water and decomposition of sulfated ions. A set of ions monitored at $m / e=18,17$ (profiles $(b, c))$ represent desorption of water which has a maximum desorption temperature below $200{ }^{\circ} \mathrm{C}$ and several peaks around $500{ }^{\circ} \mathrm{C}$ resulting from dehydroxylation of surface silanol group. Desorptions of $\mathrm{NH}_{3}$ were monitored by recording $m / e=16,15\left(\mathrm{NH}_{2}{ }^{+}\right.$and $\mathrm{NH}^{+}$ions $)$traces and shown in Fig. 2d and e. Maximum desorption appears at $250{ }^{\circ} \mathrm{C}$, and the ratio of these two peaks are consistent with standard cracking pattern of $\mathrm{NH}_{3}$ from NIST database. In Fig. 2f, a $570{ }^{\circ} \mathrm{C}$ desorption peak of the $m / e=64$ signal is due to the decomposition of the sulfate ions.

Fig. 3 shows the TPD-Mass profiles of 50SZ/MCM-41 and $5 \mathrm{~A} 50 \mathrm{SZ} / \mathrm{MCM}-41$ by monitoring $\mathrm{m} / \mathrm{e}=16$ ion from 120 to $650{ }^{\circ} \mathrm{C}$. Similar desorption temperature peaks are observed on both samples that indicating the strengths of the surface acid of these two catalysts are quite similar, even though their catalytic activities are quite different. According to the integration of desorption peaks; aluminum incorporation onto sulfated zirconia apparently
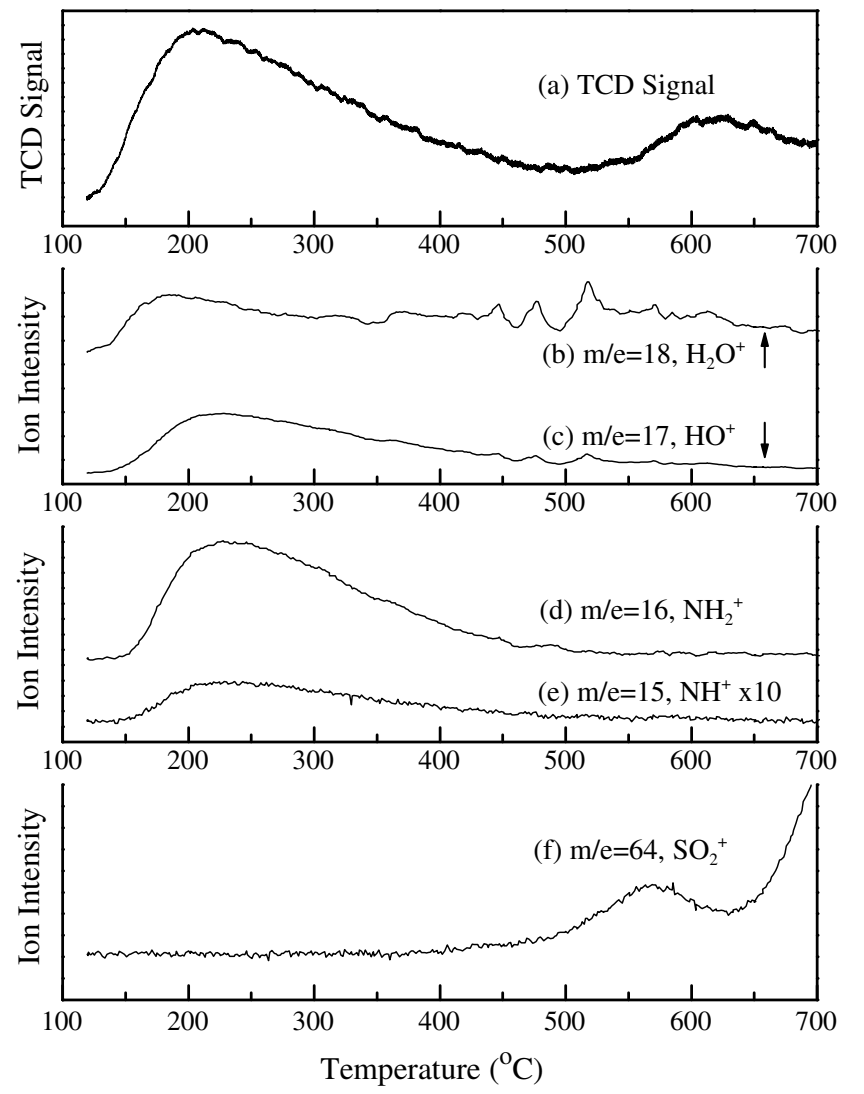

Fig. 2. The $\mathrm{NH}_{3}$-TPD-Mass profiles of $5 \mathrm{~A} 50 \mathrm{SZ} / \mathrm{MCM}-41$ : (a) TCD signal, (b) $m / e=18$, (c) $m / e=17$, (d) $m / e=16$, (e) $m / e=15$, and (f) $m / e=64$ mass ions.

increased 1.5 times in the overall amount of the acid sites while keeping similar acid strength.

\subsection{Surface components by XPS analysis}

All the alumina-promoted catalysts were investigated by XPS technique and the spectra were corrected by setting C 1 s peak at $284.6 \mathrm{eV}$ to offset the electron charging $[27,28]$. As seen from Fig. 4A, the $\mathrm{Zr} 3 \mathrm{~d}$ photoelectron peaks of 50SZ/MCM-41 and 5A50SZ/MCM-41 catalysts are sensitive to the nature of the interactions with the promoter atoms and more complicated due to the overlapping contribution of different $\mathrm{Zr}$ species. An extensive broadening and a shift to higher binding energy of the $\mathrm{Zr} 3 \mathrm{~d}$ peak occurred on the 50SZ/MCM-41. The zirconium ion density in various catalysts is expected to be about the same. Therefore, the change in the peak shape and shift in the binding energy may be attributed to different chemical environment of the measured atoms.

Pure zirconia exhibits a spin-orbit doublet of the $3 \mathrm{~d}$ core level and splits into $3 \mathrm{~d}_{5 / 2}(182.1 \mathrm{eV})$ and $3 \mathrm{~d}_{3 / 2}$ $(184.5 \mathrm{eV})$ levels with an energy gap of $2.43 \mathrm{eV}$ between them and a relative intensity ratio $\left(3 \mathrm{~d}_{5 / 2} / 3 \mathrm{~d}_{3 / 2}\right)$ of 1.5 [29]. Deconvolution of the spectra gives the existence of three kinds of zirconium species, namely species 1 , species 2 , and species 3 in decreasing binding energy. Fig. 4B 


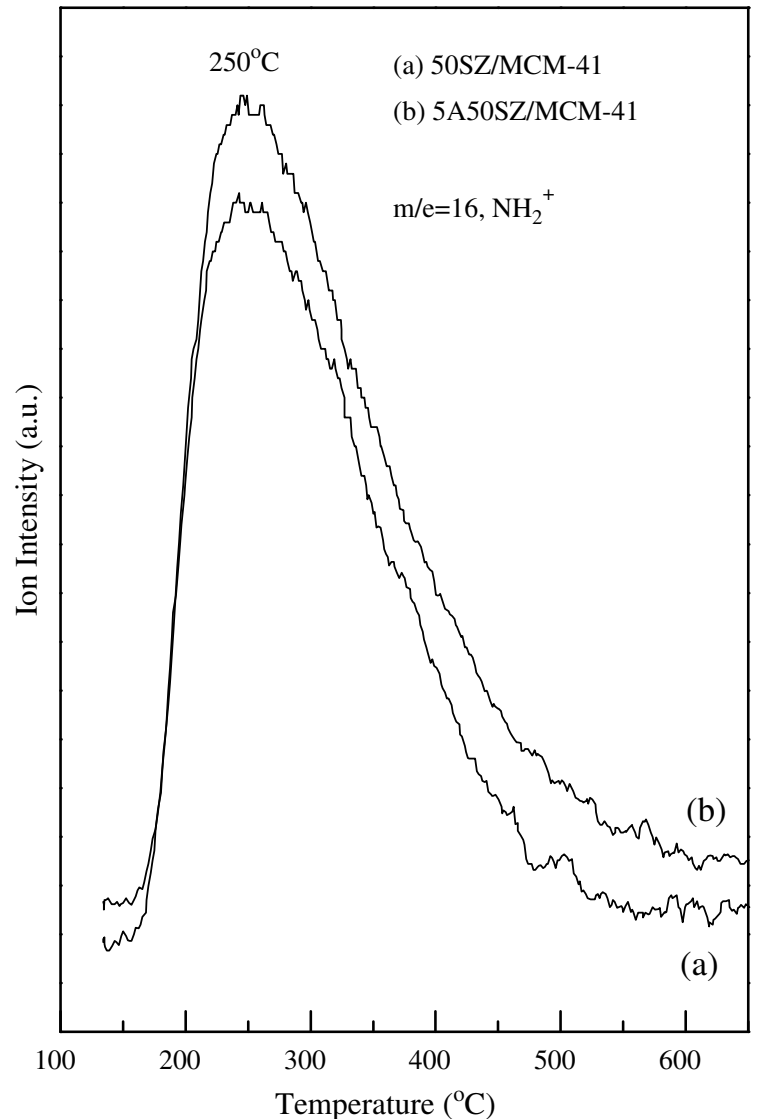

Fig. 3. The $\mathrm{NH}_{3}$-TPD-Mass profiles of: (a) 50SZ/MCM-41 and (b) $5 \mathrm{~A} 50 \mathrm{SZ} / \mathrm{MCM}-41$ by tracing the $m / e=16$ ions.

depicts the curve fitting in the de-convolution of the $\mathrm{Zr} \mathrm{3d}$ spectrum for the 5A50SZ/MCM-41 sample. A satisfactory fit with reasonable FWHM (full width half maximum) values can be achieved with three $\mathrm{Zr} 3 \mathrm{~d}$ doublets. The highest binding energy component $(183.4 \mathrm{eV})$ indicates a more positively charged $\mathrm{Zr}$ species, which is next to an electron withdrawing sulfate group, and is assigned to a Lewis acid site (species 1) [30,31]. The middle BE component (182.1 eV), assigned as species 2 , gives a $\mathrm{BE}$ value close to that of bulk zirconia [32]. The $\mathrm{BE}$ value $(180.0 \mathrm{eV})$ of species 3 , determined by curve fitting, is due to Brønsted acid. Further details about assignment of surface species are described in Section 4.

The complete deconvolution results of curve fitting corresponding to different alumina contents over $x$ A50SZ/ MCM-41 catalysts are summarized in Table 2. The values of binding energy and FWHM were used as the parameters in data analysis. From Table 2, a tendency of decreasing species 1 with increasing $\mathrm{Al}$ loading is observed.

\subsection{Morphology and calcination process}

High resolution transmission electron micrograph (HRTEM) of the catalyst 5A50SZ/MCM-41 (after calcination at $720^{\circ} \mathrm{C}$ ) is shown in Fig. 5. Well-ordered channels with continuous walls and scattered with sulfated zirconia

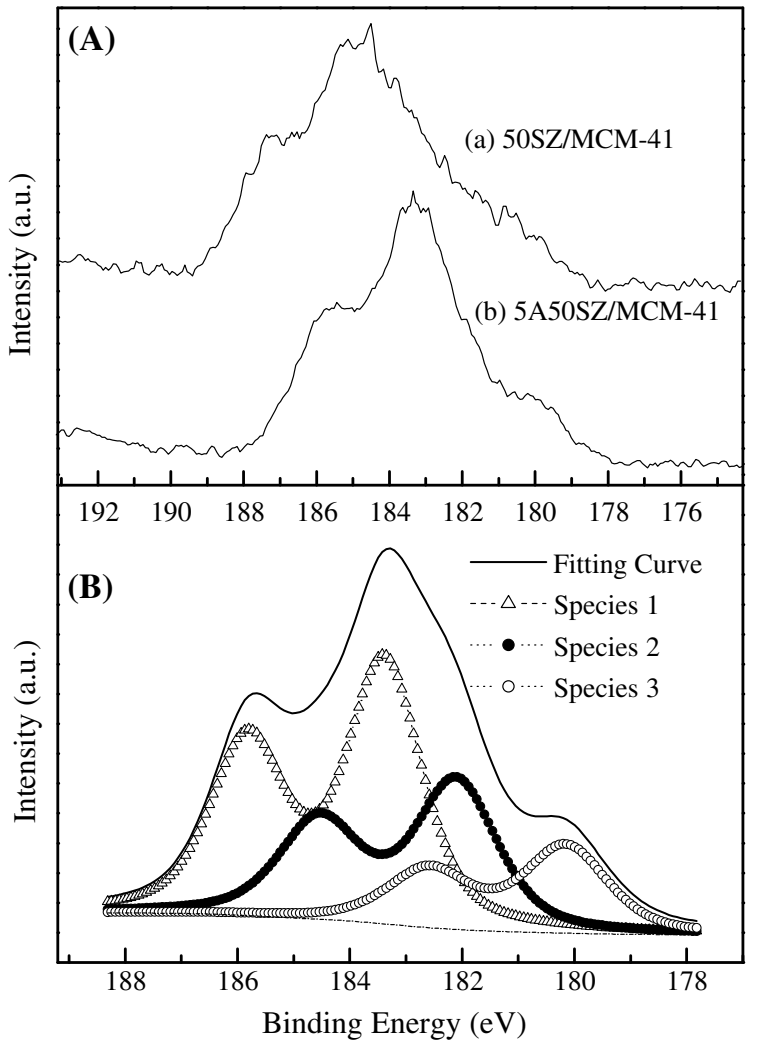

Fig. 4. (A) X-ray photoelectron spectra of $\mathrm{Zr} 3 \mathrm{~d}$ core level: (a) 50SZ/ MCM-41 and (b) 5A50SZ/MCM-41 catalysts. (B) The Zr 3d photoelectron fitted curves of 5A50SZ/MCM-41 catalyst.

nanoparticles are clearly observed. It shows the zirconium oxide not only exists in the channel of MCM-41 but also outside of the channel. The SZ particles in the square region in Fig. 5 can be seen as clearly confined within the channels of MCM-41.

Table 2

Binding energies and FWHM values of $\mathrm{Zr} 3 \mathrm{~d}$ components of various $x$ A50SZ /MCM-41 catalysts calcined at $720{ }^{\circ} \mathrm{C}$ with $x=3-7 \mathrm{~mol} \%$

\begin{tabular}{llll}
\hline Catalyst & \multicolumn{2}{l}{ Zr 3d $_{5 / 2}$ core level } & \\
\cline { 2 - 4 } & $\begin{array}{l}\text { Binding } \\
\text { energy }(\mathrm{eV})\end{array}$ & $\begin{array}{l}\text { FWHM } \\
(\mathrm{eV})\end{array}$ & $\begin{array}{l}\text { Area } \\
\text { ratio }(\%)\end{array}$ \\
\hline 3A50SZ/MCM-41 & 183.4 & 6.4 & 56 \\
& 182.1 & 6.5 & 25 \\
& 180.0 & 6.7 & 19 \\
4A50SZ/MCM-41 & 183.4 & 6.4 & 53 \\
& 182.9 & 6.4 & 30 \\
5A50SZ/MCM-41 & 180.0 & 6.8 & 17 \\
& 183.4 & 6.4 & 51 \\
& 182.1 & 6.5 & 31 \\
6A50SZ/MCM-41 & 180.1 & 6.7 & 18 \\
& 183.3 & 6.2 & 47 \\
& 182.4 & 6.2 & 38 \\
7A50SZ/MCM-41 & 180.1 & 6.7 & 15 \\
& 183.3 & 6.2 & 41 \\
& 182.1 & 6.4 & 37 \\
& 180.1 & 6.7 & 22 \\
\hline
\end{tabular}

Spin-orbit energy gap: $2.43 \mathrm{eV}$. 


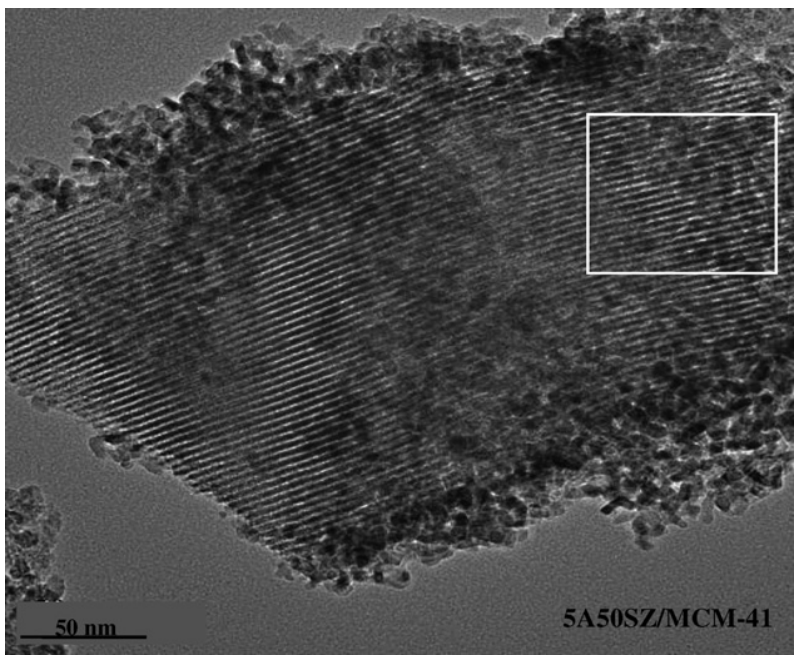

Fig. 5. The transmission electron micrograph (TEM) of calcined 5A50SZ/ MCM - 41 with a scale bar of $50 \mathrm{~nm}$.

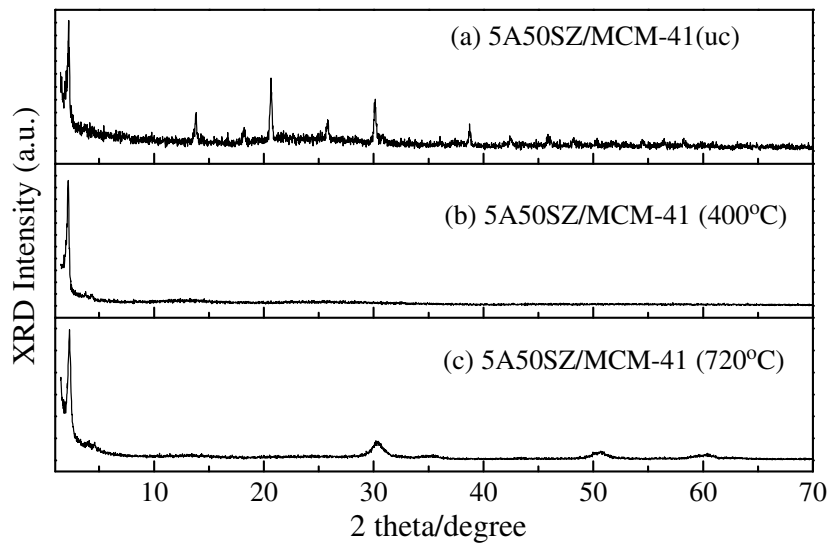

Fig. 6. The XRD profiles of 5A50SZ/MCM-41 catalyst in the: (a) initial, (b) $5 \mathrm{~h}$ at $400{ }^{\circ} \mathrm{C}$ and (c) complete the process at $720^{\circ} \mathrm{C}$ of the calcination procedure.

Fig. 6 shows the XRD profiles at different stages of calcination: (a) initial, (b) after $5 \mathrm{~h}$ at $400{ }^{\circ} \mathrm{C}$ and (c) completion of the calcinations process at $720{ }^{\circ} \mathrm{C}$. In the initial sample (Fig 6 (a)), the XRD patterns are due to a complex mixture of extracted surfactant and zirconium sulfatehydrate $\left(\mathrm{Zr}\left(\mathrm{SO}_{4}\right)_{2} \cdot 2 \mathrm{H}_{2} \mathrm{O}\right)$ in addition to the MCM-41 support. After heating at $400{ }^{\circ} \mathrm{C}$, a flat curve in the high angle regime of the Fig. 6(b) resulted from the monolayer spreading of zirconium sulfate on the surface. A decrease in the low angle diffraction peak of MCM-41 suggested a high loading of sulfated zirconia in the channels. After complete calcination, broad features of tetragonal zirconia appear in the high angle region implying very small nanoparticles are formed on the support.

\subsection{X-ray absorption spectra}

The magnitude of the FT of $k^{3} x(k)$ measured for further investigating the change of $\mathrm{Zr}$ environment during calcina-

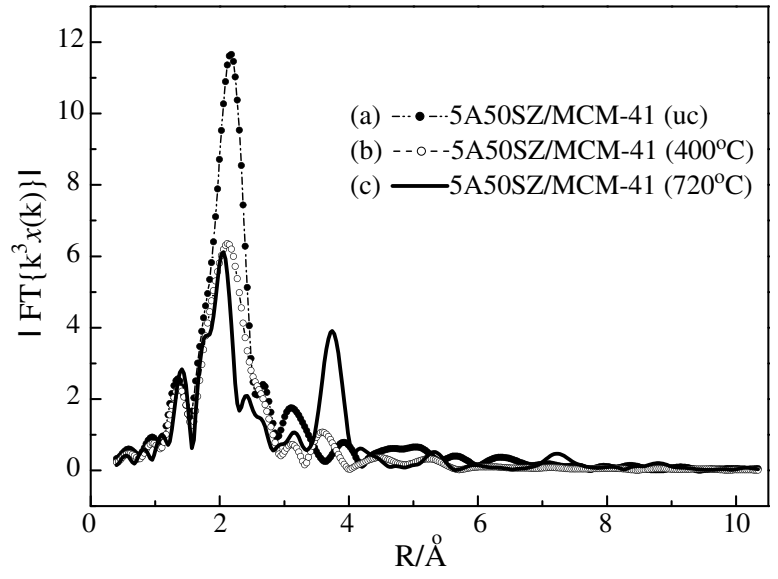

Fig. 7. The magnitude of the FT of $k^{3} x(k)$ measured at the Zr K-edge for different alumina-promoted catalysts in the (a) uncalcined, (b) $5 \mathrm{~h}$ at 400 ${ }^{\circ} \mathrm{C}$, and (c) complete overall process at $720{ }^{\circ} \mathrm{C}$ of the calcination procedure.

tion is shown in Fig. 7. The dash line with closed circles represents the 5A50SZ/MCM-41 catalyst without calcination. The feature at $\sim 1.3 \AA$ is unphysical, being too short for a realistic bond distance of $\mathrm{Zr}-\mathrm{O}$ [33-35]. The $\mathrm{Zr}$ atoms exhibit a hydroxide species and a board feature of $\mathrm{Zr}-\mathrm{O}$ coordination appears between 2.0 and $2.4 \AA$ on the curve. Very little feature due to $\mathrm{Zr}-\mathrm{O}-\mathrm{Zr}$ coordination was observed. After calcination at $400{ }^{\circ} \mathrm{C}$ for $5 \mathrm{~h}$, the zirconium hydroxide changed to an intermediate oxide species and is depicted by the dash line with open circles in Fig. 7. After calcination at $720{ }^{\circ} \mathrm{C}$, the features of the $\mathrm{Zr}-\mathrm{O}$ and $\mathrm{Zr}-\mathrm{O}$ $\mathrm{Zr}$ coordination appear at 2.1 and $3.7 \AA$, respectively, which is associated with the tetragonal crystalline of zirconia.

Next, we show the effect of alumina loading on the dispersion of zirconia. Fig. 8 shows the results of X-ray absorption study of $\mathrm{Zr}$ at various $\mathrm{Al}$ loadings. Comparing the edge energy of $\mathrm{Zr}$ foil standard with 5A50SZ/MCM-41 catalyst in Fig. 8(B), it is found the all the $\mathrm{Zr}$ in the catalyst are $\mathrm{Zr}(\mathrm{IV})$ species. As for EXAFS results, the magnitude of the Fourier transformation (FT) of $k^{3} x(k)$ measured for different alumina-promoted catalysts are shown in Fig. 8(A). The observed $\mathrm{Zr}-\mathrm{O}$ nearest peak at $\sim 2.1 \AA$ remains about the same. However, there is a clear trend of decreasing intensity of the $\mathrm{Zr}-\mathrm{O}-\mathrm{Zr}$ peak as the Al-loading is increased. This is a clear indication that alumina helps the dispersion of zirconia. Table 3 summarizes the fitted results of radial distribution for the $\mathrm{Zr} \mathrm{K}$ edge absorption of the catalysts. They are compared with various environments of $\mathrm{Zr}$ atom in the reference compounds. $R$, $N$, and $\sigma^{2}$ denote inter-atomic distance, coordination number, and Debye-Waller factor, respectively. In tetragonal zirconia, there are two kinds of $\mathrm{Zr}-\mathrm{O}$ nearest neighbors with different $\mathrm{Zr}-\mathrm{O}$ distances. Although the first neighbor distribution in our catalysts is rather broad, fitting two $\mathrm{Zr}-\mathrm{O}$ distances may not be very justified. In fact, we have tried another fitting with only one $\mathrm{Zr}-\mathrm{O}$ distance. The 


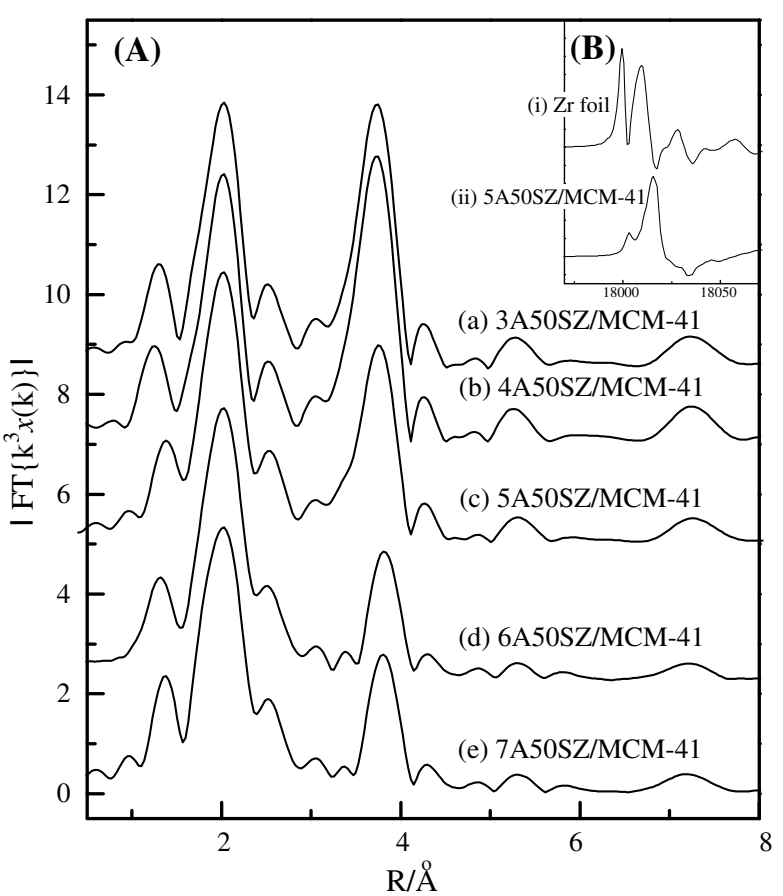

Fig. 8. (A) The magnitude of the FT of $k^{3} x(k)$ measured at the Zr K-edge for different alumina-promoted catalysts calcined at $720^{\circ} \mathrm{C}$ with: (a) 3, (b) 4, (c) 5, (d) 6, and (e) $7 \mathrm{~mol} \%$ alumina loading. (B) The differential XANES spectra of: (i) $\mathrm{Zr}$ foil and (ii) 5A50SZ/MCM-41 catalyst.

present model, with two $\mathrm{Zr}-\mathrm{O}$ distances, gives a slightly better fit and we thus report this fitting result in Table 3 . In Table 3, we also calculated the ratio of the coordination numbers of $\mathrm{Zr}-\mathrm{O}$ to $\mathrm{Zr}-\mathrm{O}-\mathrm{Zr}$ neighbors. Bulk zirconia, tetragonal or monoclinic, give high values of 1:1.5 and 1:1.57.
For Al-loaded zirconia dispersed on MCM-41, the ratio decreases as $\mathrm{Al}$ increases, indicating highly dispersed zirconia species co-exists with the nanoparticle form of zirconia.

\section{Discussion}

\subsection{Surface acidity}

Based on the characterization data in the previous section, we would like to discuss the surface features of the catalyst and to relate to catalysis activities. For interpreting the XPS and EXAFS results, a plausible surface structure model is discussed first. The coordination environment of aluminum was examined by ${ }^{27} \mathrm{Al}$ MAS NMR spectroscopy. All spectra exhibit a peak near $0 \mathrm{ppm}$, which may be assigned as octahedral coordinated aluminum formed on the surface. Only upon high Al-loadings, did a weak feature appear at $57 \mathrm{ppm}$ corresponding to tetrahedral coordination of some $\mathrm{Al}$ atoms incorporated in the framework [36].

Many reports had focused on the identification of different acid sites of sulfated zirconia $[21,37,38]$ and showed the coexistence of Brønsted and Lewis acid sites on the surface $[10,14]$. We have previously shown the activity of SZ catalyst could be influenced by $\mathrm{Al}$ addition mainly by adjusting the ratio of Lewis and Brønsted acid sites [14]. The number and strength of these acid sites vary with factors such as sulfur concentration, activation temperature, and surface area. Correlating the butane conversion activity with the ratio of Brønsted acid sites to Lewis acid sites, the remarkable activity and stability of the Al-promoted catalysts for the isomerization of $n$-butane are believed to be due to the

Table 3

EXAFS results for compounds from the literature and our work

\begin{tabular}{|c|c|c|c|c|c|}
\hline Compound & Coordination & $N$ & $R(\AA)$ & $2 \sigma^{2}\left(\AA^{2}\right)$ & $\overline{\mathrm{O}: \mathrm{Zr} \text { ratio }}$ \\
\hline st- $\mathrm{ZrO}_{2}$ & $\begin{array}{l}\mathrm{Zr}-\mathrm{O}_{\mathrm{a}} \\
\mathrm{Zr}-\mathrm{O}_{\mathrm{b}} \\
\mathrm{Zr}-\mathrm{Zr}\end{array}$ & $\begin{array}{r}4 \\
4 \\
12\end{array}$ & $\begin{array}{l}2.08 \\
2.38 \\
3.62\end{array}$ & $\begin{array}{l}0.010 \\
0.046 \\
0.018\end{array}$ & $1: 1.5$ \\
\hline$m-\mathrm{ZrO}_{2}$ & $\begin{array}{l}\mathrm{Zr}-\mathrm{O} \\
\mathrm{Zr}-\mathrm{Zr}\end{array}$ & $\begin{array}{r}7 \\
11\end{array}$ & $\begin{array}{l}2.16 \\
3.98\end{array}$ & $\begin{array}{l}0.019 \\
0.013\end{array}$ & $1: 1.57$ \\
\hline 3A50SZ/MCM-41 & $\begin{array}{l}\mathrm{Zr}-\mathrm{O}_{\mathrm{a}} \\
\mathrm{Zr}-\mathrm{O}_{\mathrm{b}} \\
\mathrm{Zr}-\mathrm{Zr}\end{array}$ & $\begin{array}{l}4.0 \\
3.9 \\
8.9\end{array}$ & $\begin{array}{l}2.10 \\
2.34 \\
3.78\end{array}$ & $\begin{array}{l}0.039 \\
0.031 \\
0.055\end{array}$ & $1: 1.13$ \\
\hline 4A50SZ/MCM-41 & $\begin{array}{l}\mathrm{Zr}-\mathrm{O}_{\mathrm{a}} \\
\mathrm{Zr}-\mathrm{O}_{\mathrm{b}} \\
\mathrm{Zr}-\mathrm{Zr}\end{array}$ & $\begin{array}{l}3.8 \\
3.6 \\
8.7\end{array}$ & $\begin{array}{l}2.11 \\
2.34 \\
3.82\end{array}$ & $\begin{array}{l}0.025 \\
0.027 \\
0.062\end{array}$ & $1: 1.17$ \\
\hline 5A50SZ/MCM-41 & $\begin{array}{l}\mathrm{Zr}-\mathrm{O}_{\mathrm{a}} \\
\mathrm{Zr}-\mathrm{O}_{\mathrm{b}} \\
\mathrm{Zr}-\mathrm{Zr}\end{array}$ & $\begin{array}{l}3.9 \\
3.7 \\
6.0\end{array}$ & $\begin{array}{l}2.10 \\
2.36 \\
3.77\end{array}$ & $\begin{array}{l}0.019 \\
0.031 \\
0.032\end{array}$ & $1: 0.78$ \\
\hline 7A50SZ/MCM-41 & $\begin{array}{l}\mathrm{Zr}-\mathrm{O}_{\mathrm{a}} \\
\mathrm{Zr}-\mathrm{O}_{\mathrm{b}} \\
\mathrm{Zr}-\mathrm{Zr}\end{array}$ & $\begin{array}{l}4.0 \\
3.9 \\
3.1\end{array}$ & $\begin{array}{l}2.08 \\
2.36 \\
3.73\end{array}$ & $\begin{array}{l}0.029 \\
0.031 \\
0.042\end{array}$ & $1: 0.38$ \\
\hline
\end{tabular}




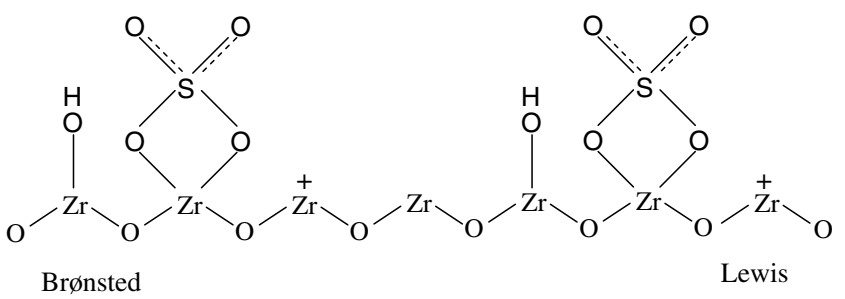

Scheme 1. The presence of both Brønsted and Lewis acid sites in the $\mathrm{SO}_{4}^{2-} / \mathrm{ZrO}_{2}$ system [39].

re-distribution of different type and strength of acid sites with an enhanced number of weak Brønsted acid sites and a decrease of Lewis and strong Brønsted acid sites [14]. Based on IR and XPS results, Ward and Ko [39] proposed structures of both Brønsted and Lewis acid sites on sulfated zirconia as shown in Scheme 1. We would like to employ this model in the following discussion.

The Brønsted acid sites on SZA result from the weakening of the $\mathrm{O}-\mathrm{H}$ bond by the neighboring sulfate group, whereas the Lewis acid sites are coordinationally deficient $\mathrm{Zr}(\mathrm{IV})$ center promoted by the electron-withdrawing neighboring sulfate group [39]. Judging from the XPS results in Table 2, surface zirconium species are classified into three types. According to the number of directly bonded oxygen, the Lewis acid sites with the most deficiency of electrons exhibit the highest binding energy value are assigned as species 1 . The species 2 represents $\mathrm{Zr}$ center with either a sulfate or Al-O- bonded to it displaying a middle value of $\mathrm{BE}$ because more oxygen atoms are connected which would have a similar binding energy as $\mathrm{Zr}-\mathrm{O}-\mathrm{Zr}$. Therefore, we used the $\mathrm{BE}$ value of bulk zirconia as the parameter to fit the species 2. The Brønsted acid sites $\mathrm{Zr}-\mathrm{OH}$ are classified as species 3. The existence of acidic $\mathrm{H}$ in $\mathrm{Zr}-\mathrm{OH}$ resulted in a decrease of binding energy. Table 2 shows that aluminum addition decreases the amount of Lewis acid sites. On the other hand, species $3(\mathrm{BE}=180.0 \mathrm{eV})$ was not observed in un-promoted SZ [30]. From ammonia TPD result, the total amounts of acid sites have a $\sim 30 \%$ enhancement with $\mathrm{Al}$ addition however. From previous reports [2,40,41], the Brønsted acid sites may be formed on the sulfate groups or as neighboring $\mathrm{Zr}-\mathrm{OH}$. Therefore, the sum of specie 2 and 3 can be regarded as the amount of Brønsted acid sites on the surface. Alumina loading would decrease the ratio of Lewis acid to Brønsted acid sites by eliminating the Lewis acid sites and forming the stronger Brønsted acid sites $\mathrm{Al}-\mathrm{OH}$ with $\mathrm{Al}$ substitution of $\mathrm{Zr}-\mathrm{OH}$ sites.

\subsection{Dispersion of sulfated zirconia}

We next investigate the dispersion process of the catalyst on the surface of the mesoporous support. A thermal stabilization of $5 \mathrm{~h}$ at $400{ }^{\circ} \mathrm{C}$ was found to be necessary to ensure complete spreading of zirconia on the surface of support [42]. The formation of the zirconia nanoparticles is associated with the migration of zirconium species at this temperature. EXAFS result (Fig. 7) indicates monolayer- like dispersion of zirconium hydroxide on the support at $400{ }^{\circ} \mathrm{C}$ that shows a decreased $\mathrm{Zr}-\mathrm{O}$ coordination which is due to partial de-hydration from hydroxide to anchor to silica surface. More importantly, we find very little $\mathrm{Zr}-\mathrm{O}-\mathrm{Zr}$ coordination at this stage indicating a highly dispersed state of $\mathrm{Zr}$. Calcination at higher temperature (720 ${ }^{\circ} \mathrm{C}$ ) is crucial to the formation and dispersion of zirconia nanoparticles. Pair distribution in Fig. 7 gives some $\mathrm{Zr}-\mathrm{O}-\mathrm{Zr}$ distribution after calcination. The pore size of MCM-41 was decreased when ASZ introduced (5A50SZ/ MCM-41 for example). The broader pore size distribution and less pore volume of 5A50SZ/MCM-41 imply that ASZ is well-dispersed on the surfaces of the mesopores of MCM-41. Zirconia nanoparticles are either confined in the inside (see the outlined area in Fig. 5) or outside the channels with a size little bigger than the pore size. It seems these nanochannels provide a large internal surface for the zirconium sulfate to spread and at the same time a steric restriction on formation of zirconium oxides nanoparticles to avoid growing to large size.

The effect of alumina on the dispersion of zirconia on MCM-41 upon calcination was investigated by EXAFS. Pure $\mathrm{t}-\mathrm{ZrO}_{2}$ is unstable at $25^{\circ} \mathrm{C}$ [43] and Table 3 shows instead stabilized zirconia $\left(\mathrm{st}-\mathrm{ZrO}_{2}\right)$ i.e. the tetragonal form stabilized with $\mathrm{Y}_{2} \mathrm{O}_{3}$ [43]. Compared with the references, we find the distance of $\mathrm{Zr}$ and $\mathrm{O}$ atoms is similar to that of st- $\mathrm{ZrO}_{2}$.

In general, the ratio of first and second shell atoms is proportional to coordination numbers around central $\mathrm{Zr}$ atom. From Table 3, the coordination number of oxygen keeps similar, but the number of neighboring zirconium changes. The coordination of second zirconium shell decreases with increasing alumina addition. The difference of $\mathrm{O} / \mathrm{Zr}$ ratio between bulk $\mathrm{ZrO}_{2}$ and $x \mathrm{~A} 50 \mathrm{SZ} / \mathrm{MCM}-41$ is due to the fact that the entire framework of bulk zirconia owns more $\mathrm{Zr}-\mathrm{O}-\mathrm{Zr}$ linkages. On the other hand, highly dispersed zirconia would decrease the second coordination. The ratio of neighboring atom of $\mathrm{O}$ to $\mathrm{Zr}$ is $1: 1.13$ at the $\mathrm{Al}$ amount of $3 \mathrm{~mol} \%$ and changes to 1:0.38 with increasing loading amount to $7 \mathrm{~mol} \%$. Notably at 6A50SZ/MCM41 , there is a sudden decrease of the ratio. This indicates an increase of the degree of dispersion of zirconia on the MCM-41.

One possible explanation of this coordination change is the differences of particle size. It is usually accepted that the averaged coordination number decreases as the particle becomes smaller. However, the particle sizes calculated from both XRD peak-width and from TEM images reveal a small decrease of the size of the zirconia as $\mathrm{Al}$ amount is increased: from $6.4 \mathrm{~nm}$ at zero $\mathrm{Al}$ to $4.7 \mathrm{~nm}$ at $4 \mathrm{~A} 50 \mathrm{SZ} /$ MCM-41; e.g. from unpromoted catalyst to 4A50SZ/ MCM-41, the particles decrease by about $30 \%$. For 5A50SZ/MCM-41 and higher Al content samples, the particle sizes of zirconia remain roughly constant. Hence, the size effect can only explain the small drop of $\mathrm{O} / \mathrm{Zr}$ ratio at small $\mathrm{Al}$ loading. For the large drop of $\mathrm{O} / \mathrm{Zr}$ ratio at 5A50SZ/MCM-41 and above, the size effect cannot be 
the sole cause responsible for such kind low $\mathrm{O} / \mathrm{Zr}$ ratio of 1:0.35. We have to look for other explanation.

The EXAFS results show all these catalysts possess a similar first coordination shell $\mathrm{Zr}-\mathrm{O}$ (see Fig. 8). In general, the total zirconium density in various catalysts is expected to be about the same since the $\mathrm{Zr}$ loadings are nearly the same. The smaller $\mathrm{O} / \mathrm{Zr}$ ratio may indicate an well-dispersed layer of zirconia upon high alumina loading in the catalyst. From the XRD results in Fig. 6, we know that at $400{ }^{\circ} \mathrm{C}$, zirconia exists as a monolayer-like dispersion on the surface of MCM-41. Further calcination at higher temperature leads to the formation of tetragonal zirconia nanoparticles. However, with alumina addition, it is quite possible the formation of $t-\mathrm{ZrO}_{2}$ is retarded. With high alumina loading, some zirconia may still exist as monlayer aftercalcination at $720{ }^{\circ} \mathrm{C}$. The monolayer or sub-monolayer zirconia spread on the channel surfaces may involve isolated zirconia clusters which reduce the second coordination. The loading of $\mathrm{Al}$ not only influences the ratio of acid sites on the catalysts, but also helps the dispersion of zirconia and varies the local structure. Previously, Jentoft and co-workers have compared the dispersion of sulfated zirconia on silica and alumina and they concluded that alumina give zirconia in higher dispersion. In addition to tetragonal zirconia, there are other $\mathrm{Zr}$ highly dispersed $\mathrm{Zr}$ species which are also catalytically active in butane isomerization [44].

\subsection{The trend in catalytic activity with respect to Al loading}

In this section, we discuss the promoting effect of alumina loadings on the catalytic isomerization of butane. First, let us compare with previous works in the catalytic activities. In the researches of Ghedini [11] and Chen [6], the activity of alumina promoted catalysts exhibit nearly the same level of conversions as ours. However, in terms of WHSV values, the optimum catalyst reported in this paper had about twice the WHSV than in [11] and [6] which implies much higher activity in our catalyst.

Then we would like to discuss the possible causes of the high activity in our Al-promoted SZ catalysts. From our characterization data presented in this paper, the effects of alumina addition may be threefold:

(1) The sulfur content in sulfated zirconia is increased upon increasing Al loading. From Table 1, we can see that sulfur content increased from $1.09 \%$ at $3 \mathrm{~A} 50 \mathrm{SZ}$ to $1.85 \%$ at $7 \mathrm{~A} 50 \mathrm{SZ}$ where the surface area is kept roughly constant. It would be thus expected that the amount of surface acid sites would increase with Al-content. But the $\mathrm{NH}_{3}$-TPD results show that the amount of surface acid increased only moderately. The increased activity then implies a change of acidic properties.

(2) Although the amount and strength of acidity only increases a little upon Al-loading according to $\mathrm{NH}_{3}$ TPD results, the distribution of the type of acidity is changed. This is revealed in the XPS data of $\mathrm{Zr}$ $3 \mathrm{~d}$ levels. From Table 2, we see that as the Al-content is increased, the relative abundance of Brønsted acid sites is increased in contrast to the decrease of Lewis acid sites. The elimination of Lewis acids by $\mathrm{Al}^{3+}$ results in more Brønsted acid sites and changes the balance of surface acid sites to further enhance the activity of catalysts. This could be due to surface binding of $\mathrm{Al}$ to zirconia [45]. Previously, with pyridine probe on ASZ catalyst, we [14] have shown the decreased ratio of Lewis and Brønsted acid sites upon Al-loading as the cause of its promotional effect. Independently, Cerrato et al. also came to the same conclusion on Ga-promoted sulfated zirconia system [46].

(3) Degree of dispersion of zirconia may be affected by Al-loading. From the analysis of EXAFS data, Table 3 shows a decrease of the ratio of neighboring $\mathrm{O} / \mathrm{Zr}$ coordination as Al-content is increased. Notably at $5 \mathrm{~A} 50 \mathrm{SZ}$, there is a sudden decrease of the ratio. This indicates an increase of the degree of dispersion of zirconia on the MCM-41. The highly dispersed zirconia monolayer may be less active in catalysis.

Putting these observations together, when the Al-loading is increased the first factor-increasing sulfur content-favors an increase of activity. However, the other two factors are not monotonic in their influences. The increase of Brønsted acid sites is at first favorable to the formation of carbenium ion and thus the isomerization rate. However, we have shown previously [14] that for optimum isomerization activity the numbers of Brønsted acid to Lewis acid sites should be balanced. Too much conversion of Lewis acid to Brønsted acid sites may not be favorable to optimum activity. Also in the case of highest Al-loading, extensive dispersion of monolayer zirconia occurs which is less active compared to the sulfated tetragonal zirconia nanoparticles.

We should note also that very recently Canton and coworkers [45] found significant increase of average residence time of the reaction intermediate upon Al-promotion leading to increased activity. It may happen that surface defects with Al-loading help the adsorption of butane intermediates. Also, the catalytic stability may be associated with hydrogen environment since catalyst deactivation was most likely caused by the accumulation of carbene fragments on the surface [47]. However, the hydrogen partial pressure may need further fine adjustment to reach best stability. In future work, the effect of hydrogen should be studied in details in the presence of promoters.

\section{Conclusion}

Alumina-promoted sulfated zirconia was successfully supported on mesoporous silica MCM-41 with direct method of impregnation followed by solid-state dispersion of the corresponding metal sulfate. Ordered mesoporous 
materials with large surface area are beneficial towards supporting a large amount of zirconium sulfate and its decomposition in forming tetragonal sulfated zirconia nanoparticles which is the catalytic active phase in the isomerization of hydrocarbon. The nanochannels of MCM-41 provide a steric restriction on limiting the sizes of large zirconia nanoparticles.

With a proper amount of aluminum as the promoter, the transformation of zirconia from the meta-stable tetragonal phase to monoclinic phase was retarded and enhanced the catalytic activity for $n$-butane conversion. At the same time, the amount of sulfate loading is increased leading to more acidic sites. However, with too high a Al-loading, it may have also retarded the transformation of monolayer state to tetragonal zirconia leading to less activity.

The EXAFS results show the relative amount of oxygen deficiency is controlled by $\mathrm{Al}$ loading which affects the balance of Lewis and Brønsted acid sites. This result is in agreement with XPS analysis of surface $\mathrm{Zr}$ species. The XPS analysis indicates that Lewis acid sites were the predominant sites on unpromoted catalyst and decreases with $\mathrm{Al}$ addition while Brønsted acid sites increase. These results support the hypothesis that the acid sites on catalysts are a combination of Lewis and Brønsted acid sites and their relative amount varies with $\mathrm{Al}$ loading. The promotion effects of alumina on SZ in butane isomerization are explained based on three factors: increased sulfur retention, balanced distribution of Lewis and Brønsted acid sites, and higher dispersion of zirconia.

Finally, we note that the Ga-promoted SZ/MCM-41 catalyst is also a new kind of solid acid catalyst with substantial mesoporous surface $[46,48]$. It has a high catalytic activity for $n$-butane isomerization and better stability in activity. Present study of the Al-promoted catalyst may be extended to the Gallium-promoted catalytic system $[48,49]$. A full understanding of the metal-promoted sulfated zirconia catalysts may help one to design a highly active and steady catalyst for alkane isomerization.

\section{Acknowledgments}

This work was supported by a grant from the Ministry of Education through Academy Excellent program. Discussions with Prof. Chang-lin Chen and Dr. S.T. Wong are acknowledged. Dr. S.J. Huang is thanked for his help in ${ }^{27} \mathrm{Al}$ NMR experiments. We thank the NSRRC for providing the synchrotron beam time, Dr. J.F. Lee, Dr. M.T. Tang and Mr. D.K. Liu for kindly helps during the EXAFS measurements.

\section{References}

[1] X. Song, A. Sayari, Catal. Rev. 38 (3) (1996) 329

[2] B.H. Davis, R. Keogh, R. Srinivasan, Catal. Today 20 (1994) 219.

[3] A. Corma, M.I. Juan-Rajadell, J.M. Lopez Nieto, Appl. Catal. A. 116 (1994) 151

[4] Y.Y. Sun, S.Q. Ma, Y.C. Du, L. Yuan, S.C. Wang, J. Yang, F. Deng, F.S. Xiao, J. Phys. Chem. B 109 (2005) 2567.
[5] C.L. Chen, C.Y. Mou, Mesoporous materials as catalyst supports, in: Bing Zhou, Sophie Hermans, Gabor A. Somorjai (Eds.), Nanotechnology in Catalysis, Kluwer/Plenum, 2001.

[6] C.L. Chen, S. Cheng, H.P. Lin, S.T. Wong, C.Y. Mou, Appl. Catal. A 215 (2001) 21.

[7] Y. Sun, L. Zhu, H. Lu, R. Wang, S. Lin, D. Jiang, F.-S. Xiao, Appl. Catal. A 237 (2002) 21.

[8] W. Wang, C.L. Chen, N.P. Xu, S. Han, T. Li, S.F. Cheng, C.Y. Mou, Catal. Lett. 83 (2002) 281

[9] C.L. Chen, T. Li, S. Cheng, N.P. Xu, C.Y. Mou, Catal. Lett. 78 (2002) 223.

[10] W. Wang, J.H. Wang, C.L. Chen, N.P. Xu, C.Y. Mou, Catal. Today 97 (2004) 307.

[11] E. Ghedini, M. Signoretto, F. Pinna, G. Cerrato, C. Morterra, Appl. Catal. B 67 (2006) 24.

[12] Z. Gao, Y. Xia, W. Hua, C. Miao, Topics Catal. 6 (1998) 101.

[13] C.J. Cao, X.Z. Yu, C.L. Chen, N.P. Xu, Y.R. Wang, C.Y. Mou, Reac. Kin. Catal. Lett. 83 (2004) 85.

[14] J.H. Wang, C.Y. Mou, Appl. Catal. A 286 (2005) 128.

[15] J.A. Moreno, G. Poncelet, J. Catal. 203 (2001) 453.

[16] Y. Sun, S. Walspurger, B. Louis, J. Sommer, Appl. Catal. A 292 (2005) 200

[17] X. Yang, F.C. Jentoft, R.E. Jentoft, F. Girgsdies, T. Ressler, Catal. Lett. 81 (2002) 25.

[18] W. Hua, Y. Xia, Y.Y. Yue, Z. Gao, J. Catal. 196 (2000) 104.

[19] C.L. Chen, T. Li, S.F. Cheng, H.P. Lin, C.J. Bhongale, C.Y. Mou, Micro. Mesop. Mater. 50 (2001) 201

[20] K. Arata, Adv. Catal. 37 (1990) 165

[21] T. Yamaguchi, Appl. Catal. 61 (1990) 1.

[22] C. Morterra, G. Cerrato, F. Pinna, M. Signoretto, J. Catal. 157 (1995) 109.

[23] P. Canton, R. Olindo, F. Pinna, G. Strukul, P. Riello, M. Meneghetti, G. Cerrato, C. Morterra, A. Benedetti, Chem. Mater. 13 (5) (2001) 1634.

[24] A. Corma, V. Fornes, M.I. Juan-Rajadell, J.M. Lopez Nieto, Appl. Catal. A 116 (1994) 151.

[25] T. Hosoi, T. Shiidzu, S. Itoh, S. Baba, H. Takaoka, T. Imai, N. Yokoy-ama, Prepr. Am. Chem. Soc. Div. Pet. Chem. 33 (1988) 562.

[26] T. Okuhara, T. Nishimura, H. Watanabe, M. Misono, J. Mol. Catal. 74 (1992) 247.

[27] D. Briggs, M.P. Seah (Eds.), Practical Surface Analysis, Auger and X-ray Photoelectron Spectroscopy, 2nd ed., vol. 1, Wiley, New York, 1990.

[28] C.D. Wagner, W.M. Riggs, L.E. Divis, J.F. Moulder, G.E. Muilenberg (Eds.), Handbook of X-ray Photoelectron Spectroscopy, PerkinElmer Corporation, Minnesoda, 1978.

[29] S. Ardizzone, C.L. Bianchi, Surf. Inter. Anal. 30 (2000) 77.

[30] S. Ardizzone, C.L. Bianchi, M. Signoretto, Appl. Surf. Sci. 136 (1998) 213.

[31] B.M. Reddy, B. Chowdhury, P.G. Smirniotis, Appl. Catal. A: General 211 (2001) 19.

[32] C. Defosse, P. Canesson, J. Chem. Soc., Faraday Trans. 1 (1976) 2565.

[33] J. Mustre de Leon, S.I. Zabinsky, R.C. Albers, Phys. Rev. B 52 (1995) 2995.

[34] W.C. Wang, Y. Chen, Phys. Status Solids A 168 (1998) 351.

[35] G. Antonioli, P.P. Lottici, I. Manzini, G. Gnappi, A. Montenero, F. Paloschi, F.P. Parent, J. Non-Cryst. Solids 77 (1994) 179.

[36] R. Mokaya, W. Jones, Phys. Chem. Chem. Phys. 1 (1999) 207.

[37] M. Scheithauer, R.K. Grasselli, H. Knozinger, Langmuir 14 (1998) 3019.

[38] C.D. Baertsch, S.L. Soled, E. Iglesia, J. Phys. Chem. B 105 (2001) 1320.

[39] D.A. Ward, E.I. Ko, J. Catal. 150 (1994) 18.

[40] S. Xiao, R. Le Van Mao, Micropor. Mater. 4 (1995) 435.

[41] J.M. Parera, Catal. Today 15 (1992) 481.

[42] Y.Y. Huang, B.Y. Zhao, Y.C. Xie, Appl. Catal. A 173 (1998) 27.

[43] P. Li, I.-W. Chen, J.E. Penner-Hahn, Phys. Rev. B 48 (1993) 10063. 
[44] X. Yang, R.E. Jentoft, F.C. Jentoft, Catal. Lett. 106 (2006) 195.

[45] S.Y. Kim, N. Lohitharn, J.G. Goodwin, R. Olindo, F. Pinna, P. Canton, Catal. Commun. 7 (2006) 209.

[46] G. Cerrato, C. Morterra, M.R. Delgado, C.O. Arean, M. Signoretto, F. Somma, F. Pinna, Micro. Mesop. Mater. 94 (2006) 40.
[47] D.J. Zalewski, S. Alerasool, P.K. Doolin, Catal. Today 53 (1999) 419.

[48] W. Wang, C.L. Chen, N.P. Xu, C.Y. Mou, Green Chem. 4 (2002) 257.

[49] C.J. Cao, S. Han, C.L. Chen, N.P. Xu, C.Y. Mou, Catal. Commun. 4 (2003) 511 